\title{
EBV DNA in Nonlymphoid Cells of Nasopharyngeal Carcinomas and in a Malignant Lymphoma Obtained after Inoculation of EBV into Cottontop Marmosets
}

\author{
H. WOLF, J. WERNER* AND H. zUR HAUSEN \\ Institut für Klinische Virologie, der Universität Erlangen-Nürnberg and *Robert-Koch-Institut, Berlin, Germany
}

\begin{abstract}
Epstein-Barr viral (EBV) DNA has been regularly demonstrated in biopsy material from two different human tumors: Burkitt's lymphoma and nasopharyngeal carcinoma (zur Hausen et al. 1970, 1974b; Nonoyama and Pagano 1973; Wolf et al. 1973). Patients carrying either of these tumors reveal elevated antibody titers against $\mathrm{EB}$ viral capsid antigens (VCA) and in a high percentage also against EBV early antigens (EA) (Henle et al. 1970a,b).
\end{abstract}

In Burkitt's lymphoma cells, EBV-specific membrane antigens (Gunvén et al. 1970) as well as EB-associated nuclear antigens (EBNA) have been demonstrated (Reedman and Klein 1973; Reedman et al. 1974). The transforming potential of EBV for lymphatic cells has been shown in vitro (Henle et al. 1967; Pope et al. 1968). Recently the susceptibility of immunoglobulin-synthesizing lymphocytes has been convincingly demonstrated (Klein et al., unpubl.; Schneider and zur Hausen 1975). It appears that type T lymphocytes lack receptors for EBV absorption (Jondal and Klein 1973).

$A$ variety of non-Burkitt type $B$ lymphomas do not contain EBV-specific nucleic acids and antigens (Lindahl et al. 1974), despite the presence of EBV antibodies and the apparent persistence of the virus in cells of the peripheral blood. This provides further indirect evidence for the unique role of $\mathrm{EBV}$ in Burkitt's lymphoma.

Nasopharyngeal carcinomas contain, in contrast io Burkitt's lymphoma, a mixed cell population. Islands of nonlymphatic epithelial tumor cells are infiltrated to a varying extent by lymphocytes (Shanmugaratnam 1972). The degree of lymphatic infiltration has even been used to subclassify this tumor, which was originally named "lymphoepithelioma." The rather well known "lymphotropism" of EBV suggested to some investigators that the viral DNA demonstrated in these tumors by nucleic acid hybridizations should be located within the infiltrating lymphocytes (McAllister 1973). Thus the nonlymphoid tumor cells would not contain virus-specific products.

Previous data from our laboratory were at variance with this interpretation (Wolf et al. 1973). They revealed the presence of viral DNA within epithelial cells of the two tumors examined by in situ hybridizations and anticomplementary im- munofluorescence. The following is an extension of these studies which establishes further the presence of EB viral DNA within the tumor cells of nasopharyngeal carcinomas.

In addition, the recent induction of lymphoproliferative disease by EBV in marmosets (Shope et al. 1973) and an owl monkey (Epstein et al. 1973) stimulated us to similar experiments. It was our intention to infect primates with virus isolates from different virus-producing lymphoblastoid lines and to demonstrate virus-specific nucleic acids within the tumor material of such animals. The following report summarizes the results.

\section{MATERIAL AND METHODS}

Cells. P3HR-1 cells of Burkitt's tumor origin (Hinuma et al. 1967) and Kaplan cells derived from a patient with infectious mononucleosis (Diehl et al. 1968) were both obtained from Werner Henle, Philadelphia. They were kept in medium RPMI 1640 supplemented with $10 \%$ fetal calf serum.

Virus preparations. Methods of viral purification and extraction of viral DNA have been reported before (SchulteHolthausen and zur Hausen 1970; zur Hausen et al. 1970). Methods of filter hybridizations with virus-specific complementary RNA (cRNA) and of in situ hybridizations were also reported elsewhere (zur Hausen et al. 1974a). Indirect immunofluorescence to determine $\mathrm{EBV}$-specific antibodies against viral capsid antigens and the early antigen complex was performed according to Henle et al. (1971).

Collection of tumor specimens and DNA extraction. All tumor materials were obtained through the courtesy of G. Klein, Stockholm and S. Singh, Nairobi. They were shipped to Erlangen in ice water immediately after surgical removal. The method of DNA extraction has been reported (zur Hausen et al. 1970).

Labeling of EBV DNA. The method of Dumas et al. (1971) and Nonoyama and Pagano (1973) was followed with minor modifications. EBV DNA $(1.5 \mu \mathrm{g})$ was incubated for $15 \mathrm{~min}$ at $37^{\circ} \mathrm{C}$ in a volume of $0.5 \mathrm{ml}$ containing 0.05 $\mu \mathrm{g}$ pancreatic DNase, $10 \mathrm{~mm} \mathrm{MgCl} 1 \mathrm{~mm}$ mercaptoethanol, $0.05 \mathrm{M}$ Tris, $10 \mathrm{mM} \mathrm{CaCl}_{2}$ and $1 \mathrm{~mm} \mathrm{Na}$ citrate. The reaction was stopped by incubating the mixture for $10 \mathrm{~min}$ at $70^{\circ} \mathrm{C}$. After chilling the solution, $10 \mu \mathrm{l}$ DNA polymerase I (containing 1.5 units of the enzyme in $50 \%$ glycerol) was added and the total volume was increased to $0.75 \mathrm{ml}$, now 
containing 100 nmoles each of dATP and dGTP, 10 nmoles each of $\left[{ }^{3} \mathrm{H}\right] \mathrm{dTTP}$ (spec. act. $45 \mathrm{Ci} / \mathrm{mmole}$ ) and $\left[{ }^{3} \mathrm{H}\right] \mathrm{dCTP}$ (spec. act. $13.3 \mathrm{Ci} / \mathrm{mmole}$ ), $10 \mathrm{~mm} \mathrm{~K} \mathrm{KPO}_{4}, 0.05 \mathrm{~m}$ Tris, $75 \mathrm{mM} \mathrm{MgCl}_{2}, 0.73 \mathrm{~mm}$ mercaptoethanol, $6.7 \mathrm{~mm} \mathrm{NaCl}$ and $0.7 \mathrm{~mm} \mathrm{Na}$ citrate. The $\mathrm{pH}$ was adjusted to 7.4. After further incubation at $17^{\circ} \mathrm{C}$ for $2 \mathrm{hr}$ followed by phenol extraction, the material was chromatographed on a Sephadex G50 column. Approximately $0.43 \%$ of the radioactivity was found to be acid insoluble. The specific activity of the DNA was calculated to amount to $1.26 \times 10^{6}$ $\mathrm{cpm} / \mu \mathrm{g}$.

Reassociation kinetics of hybridization. The procedure of Britten and Kohne (1971) and of Gelb et al. (1971) was followed with minor modifications. One mg cellular DNA was dissolved in $0.5 \mathrm{ml}$ containing $1 \mathrm{M} \mathrm{NaCl}, 0.5 \mathrm{M}$ Tris $\mathrm{pH} 7.4,0.01 \mathrm{M}$ EDTA, $0.05 \%$ sarcosyl and $10 \mathrm{ng}$ radioactive EBV DNA and sonified for $3 \times 10 \mathrm{sec}$ at $70 \mathrm{w}$ by using the Branson microtip sonifier. Fifty $\mu l$ samples were brought into capillaries and then again sonified for $10 \mathrm{~min}$ at $100 \mathrm{w}$ with the macrotip of the Branson sonifier. The capillaries were then incubated $10 \mathrm{~min}$ at $120^{\circ} \mathrm{C}$ in diethyleneglycol. Since additional experiments revealed that EBV DNA melted under these conditions at a $T_{m}$ of $97^{\circ} \mathrm{C}$, incubation was continued at a temperature of $73^{\circ} \mathrm{C}$ (Wetmur and Davidson 1968).

After varying periods of incubation, the samples were chromatographed on hydroxylapatite columns at $60^{\circ} \mathrm{C}$ by adding consecutively $4 \times 0.5 \mathrm{ml}$ and $1 \times 1 \mathrm{ml}$ of $0.14 \mathrm{M}$ phosphate buffer containing $0.4 \%$ sodium dodecyl sulfate (SDS). Double-stranded DNA was eluted with $3 \times 0.5 \mathrm{ml}$ 0.4 м phosphate buffer.

\section{RESULTS AND DISCUSSION}

\section{EBV DNA in Nasopharyngeal Carcinomas}

DNA from biopsies of 34 nasopharyngeal carcinomas was hybridized with EBV cRNA. Eleven of these tumors annealed to a higher extent than DNA derived from Raji cells, a non-virus-producing lymphoblastoid line which was shown in previous experiments to harbor approximately 50 genome equivalents of EBV DNA (Nonoyama and Pagano 1971; zur Hausen et al. 1972). Only three tumor materials were entirely negative in this test. A careful histological reexamination of remaining material from these biopsies did not reveal any tumorous tissue in two of these, whereas the third one represented an adenocarcinoma.

The careful histological analysis of the tumors showed that all highly hybridizing tumors were of predominantly epithelial morphology, whereas lymphatic cells represented a majority in most of the remaining biopsies. This was in agreement with our previous findings (Wolf et al. 1973) suggesting the presence of EBV DNA within epithelial tumor cells, and was further substantiated by in situ hybridizations of cytological preparations.

For this purpose, tumors were selected which contained almost equal amounts of epithelial and lymphatic cells. A nonhybridizing tumor served as control. Freeze sections of these materials were treated with RNase, alkali-denatured, incubated with EBV cRNA, again treated with RNase and then exposed to autoradiography (Wolf et al. unpubl.). The result is shown in Figure 1. Regions of large, pale nuclei are obviously preferentially labeled. Such regions correspond to nonlymphoid cells in the nondenatured sections. No labeling was observed within the control material. These results further confirm and clarify the specific association of EBV with epithelial nasopharyngeal carcinoma cells. The labeling of nonlymphoid cells appears to be confined to the nuclear region, although the denaturation procedure affects the morphology of the cells. These data do not, of course, preclude that some of the lymphoid cells in the nasopharyngeal tumors also carry viral DNA, particularly since EBV-synthesizing lymphoblastoid cell lines have been established from some of these tumors. Additional experiments reveal, however, that the EBV DNA content of the lymphoid fraction in nasopharyngeal carcinomas must be very small and therefore escapes detection in many instances: Recently Claude Desgranges (International Agency for Research on Cancer, Lyon) fractionated cells from nasopharyngeal carcinomas in Ficoll gradients and separated lymphocytes from the remaining tumor cells. From three such tumors, sufficient DNA was obtained to test separately the DNA of the lymphocytic and epithelial fractions. Hybridization of these samples with EBV cRNA was carried out in our laboratory. The data revealed a convincing picture: no significant hybridization was found within the lymphocyte DNA, whereas all three epithelial preparations annealed clearly above the range of Raji cell DNA.

Furthermore, hybridization of DNA from leukocytes of the peripheral blood of patients with nasopharyngeal carcinomas with EBV cRNA did not result in significant annealing. Thus it appears to be firmly established that nasopharyngeal carcinoma represents the second human malignancy, in addition to Burkitt's lymphoma, in which viral DNA can be regularly demonstrated within the tumor cells. Besides the infection of type B lymphocytes (Jondal and Klein 1973), EBV obviously infects specific additional cells of apparently epithelial morphology.

\section{EBV Induction of a Malignant Lymphoma in a Cottontop Marmoset}

Shope et al. (1973) and Epstein et al. (1973) induced tumors in marmosets or an owl monkey by injecting them with EBV derived from a marmoset line transformed in vitro by EBV (Miller et al. 1972) or with virus obtained from a Burkitt's lymphoma line. It was our intention to test whether or not EBV directly derived from Kaplan cells, a lymphoblastoid line from a patient with infectious mononucleosis (Diehl et al. 1968), was also able to 


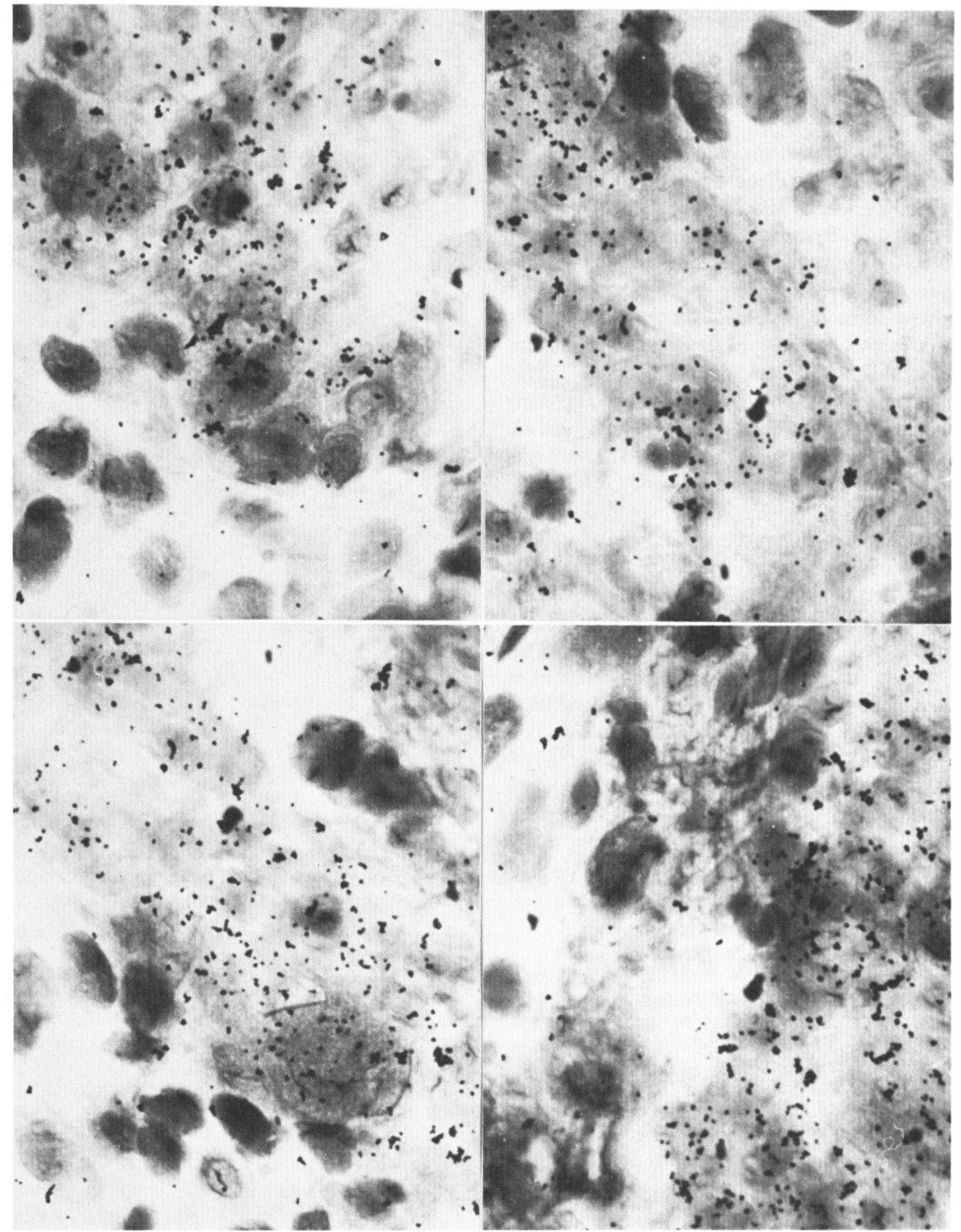

Figure 1. In situ hybridization of EBV cRNA with freeze sections of a nasopharyngeal carcinoma. Hybridization was performed with 50,000 cpm of EBV cRNA in a volume of $50 \mu \mathrm{l}$. Note the grains on large, pale nuclei which correspond to nonlymphoid cells in nondenatured sections.

induce tumors in vivo. In the event of tumor development, we wanted to test the biopsy material for the presence of EBV genomes.

EBV was concentrated from the supernatants of Kaplan and P3HR-1 cells. Part of each preparation was preincubated with human serum containing high titers against EBV-specific antigens. The remaining part was similarly treated with human serum devoid of detectable EBV antibody activity.

Two groups of three cottontop marmosets each received either the non-neutralized Kaplan concentrate or the P3HR-1 preparation. Similarly, two groups of two cottontop marmosets obtained the neutralized preparations of the respective virus isolates. The virus was injected into the $M$. masseter. The animals were bled weekly and examined for the development of EBV antibodies by indirect immunofluorescence.

Seven weeks after inoculation, one of the animals which received the non-neutralized Kaplan virus 
developed symptoms of lymphoproliferative disease. It was sacrificed 2 weeks later and autopsied. A solid tumor was found in the submandibular region. In addition, regional lymph nodes and spleen revealed hyperplasia.

Histological examination of the tumor and serveral organs of the diseased animal was performed by Dr. Becker of the Department of Pathology, University of Erlangen. The tumor material (Fig. 2) exhibited characteristics of a lymphosarcoma with numerous necrotic foci. Lymph nodes and spleen showed some hyperplasia but no typical foci of tumorous tissue. Some lymphocytic infiltrations were recognizable within the liver material.

DNA from tumor, spleen, thymus and lymph nodes was extracted and subjected to EBV cRNA hybridizations. We failed to detect significant annealing with any of these preparations, probably due to the insensitive assay since previous reconstruction tests had shown that this EBV cRNA could not detect less than three genome equivalents per cell. In order to increase the sensitivity of the assay, EBV DNA was labeled in vitro and used in $\mathrm{C}_{0} \mathrm{t}$ hybridizations with the same material. The result is shown in Figure 3. The input of labeled viral DNA used in this test with $2 \mathrm{mg}$ of cellular DNA corresponded to 0.3 genome equivalent per cell. The artificial admixture of $40 \mathrm{ng} / \mathrm{ml}$ of EBV DNA should correspond to 1.08 genome equivalents per cell, the $200 \mu \mathrm{g} / \mathrm{ml}$ of Raji DNA to 5 genome equivalents per cell. The figure shows that DNA derived from the tumor material contained slightly more than one genome equivalent of EBV DNA.

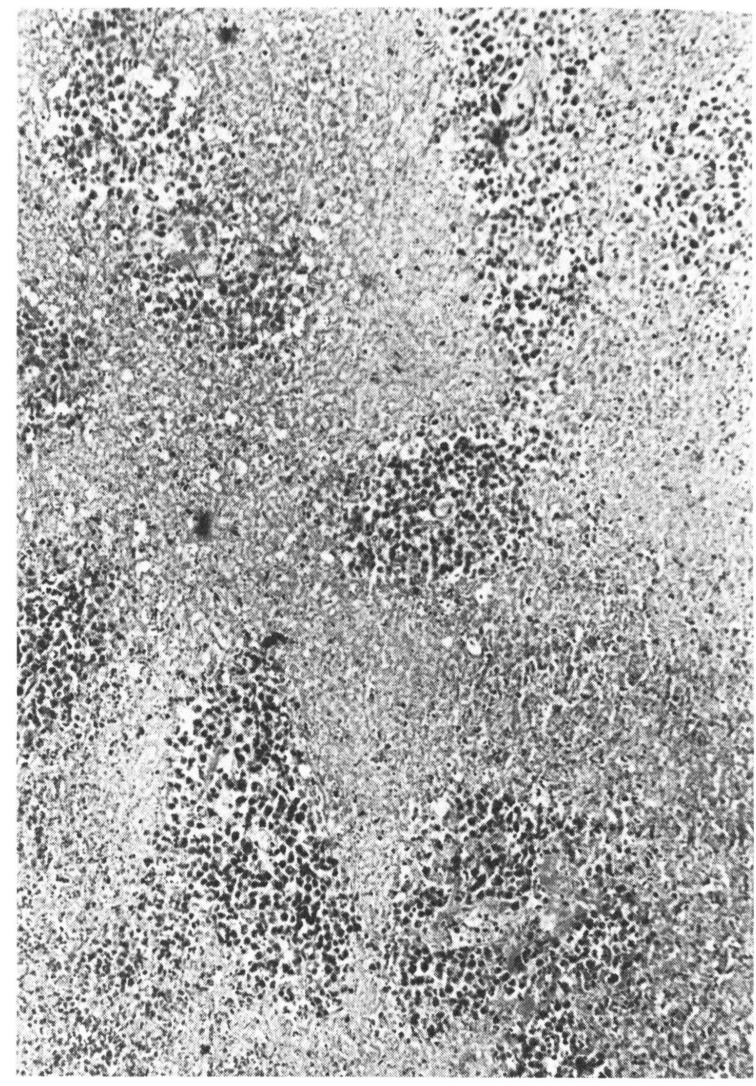

Figure 2. Histology of the marmoset tumor induced by EBV derived from Kaplan cells. Note the relative scarcity of tumor cells and the extended necrotic areas.

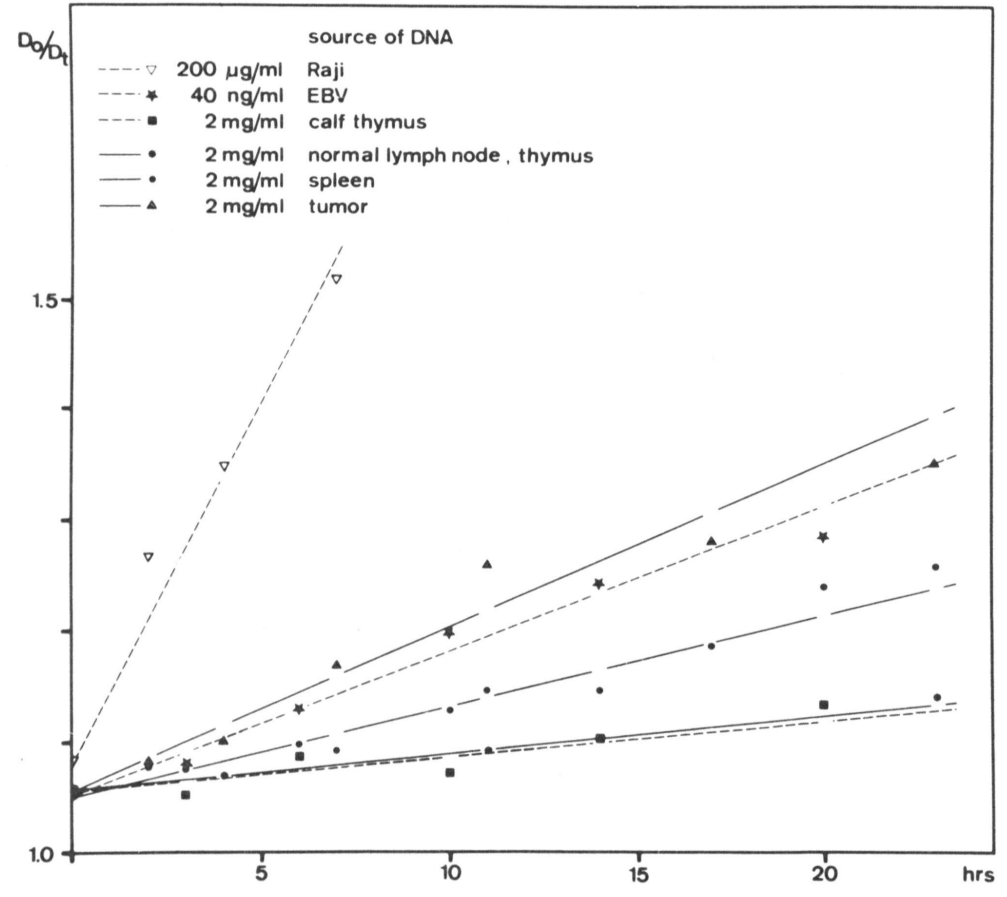

Figure 3. $\mathrm{C}_{0} \mathrm{t}$ analysis of in vitrolabeled EBV DNA in the presence of DNA derived from tumor and spleen of the tumor-bearing marmoset. Additional controls are indicated in the figure. 
Approximately 0.5 genome equivalent was found in the spleen DNA, whereas the DNA mixture from the thymus and unaffected lymph nodes did not enhance the reassociation reaction.

In view of the relative scarcity of tumor cells within the tumor material, the actual concentration of viral DNA should be 4-5 times higher than calculated from the reassociation assay. In situ hybridizations performed on freeze sections of the tumor material failed to reveal significant clustering of grains. This is not surprising since this method represents a rather insensitive assay. It should exclude, however, viral particle synthesis in a few permissive cells as a reason for the observed amount of EBV-specific DNA.

Lymphoblastoid cell lines were obtained from the tumor as well as from spleen material. Approximately $3 \%$ of these cells synthesize spontaneously EB viral capsid antigens as observed by immunofluorescence. Typical herpesvirus particles were also found by electron microscopy, and the hybridization rate with $\mathrm{EBV}$ cRNA was in the range of the virus-producing P3HR-1 line. Recently, transformation of human umbilical cord lymphocytes was achieved with cell-free virus obtained from these lines.

None of the nine additional cottontop marmosets inoculated either with non-neutralized or neutralized Kaplan or P3HR-1 virus have developed tumors up to now. Except for the tumor-bearing marmoset, no rise in antibodies against EBV antigens was observed in any of the other animals. Even the tumor-carrying marmoset revealed a rather low titer against $\mathrm{EB}$ viral capsid antigens. Our failure to detect significant levels of EBV antibodies could be due to the use of FITC-coupled, anti-human $\gamma$-globulin, since we had no access to anti-cottontop marmoset $\gamma$-globulin.

\section{CONCLUSION}

Our results show that EBV DNA can be regularly demonstrated in nonlymphoid epithelial nasopharyngeal carcinoma cells. Therefore nasopharyngeal carcinoma represents the second human malignancy, in addition to Burkitt's lymphoma, which contains the DNA of a transforming and oncogenic virus within the tumor cells.

It was also shown that EBV derived from a patient with infectious mononucleosis induced a lymphosarcoma in a cottontop marmoset, that viral DNA was found in the tumor material, and that virusspecific antigens as well as typical herpesvirus particles were present in lymphoblastoid cells obtained from the tumor material and kept in tissue culture.

\section{Acknowledgments}

The authors are indebted to Dr. George Klein,
Stockholm, and Mr. Surjit Singh, Nairobi, for providing the tumor biopsy material. We gratefully appreciate the histological evaluation of the tumors by Dr. Volker Becker, Erlangen. This work was supported by the Deutsche Forschungsgemeinschaft (SFB 118).

\section{References}

Britten, R. J. and D. E. Kohne. 1971. Repeated sequences in DNA. Science 161: 529.

Diehl, V., G. Henle, W. Henle and G. Kohn. 1968. Demonstration of a herpesgroup virus in cultures of peripheral leucocytes from patients with infectious mononucleosis. J. Virol. 2: 663.

Dumas, L. B., G. Darby and R. L. Sinsheimer. 1971. The replication of bacteriophage $\phi \times 174$ DNA in vitro. Temperature effects on repair synthesis and displacement synthesis. Biochim. Biophys. Acta 228: 407.

Epstein, M. A., R. D. Hunt and H. Rabin. 1973. Pilot experiments with EBV in owl monkey (Aotus trivir. gatus). I. Reticuloproliferative disease in an inoculated animal. Int. J. Cancer 12: 309.

GelB, L. D., D. E. Kohne and M. Martin. 1971. Quantitation of simian virus 40 sequences in African green monkey, mouse and virus-transformed cell genomes. J. Mol. Biol. 57: 129.

Gunvén, P., G. Klein, G. Henle, W. Henle and P. ClifFORD. 1970. Antibodies to EBV associated membrane and viral capsid antigens in Burkitt lymphoma patients. Nature 228: 1053.

Henle, G., W. Henle and G. Klein. 1971. Demonstration of two distinct components in the early antigen complex of Epstein-Barr virus infected cells. Int. J. Cancer 8: 272 .

Henle, W., V. Diehl, G. Kohn, H. zur Hausen and G. Henle. 1967. Herpes-type virus and chromosome marker in normal leukocytes after growth with irradiated Burkitt cells. Science 157: 1064.

Henle, W., G. Henle, B. A. Zajac, G. Pearson, R. Waubke and M. SCrIBA. 1970a. Differential reactivity of human serums with early antigens induced by Epstein-Barr virus. Science 169: 188.

Henle, W., G. Henle, H. C. Ho, P. Burtin, Y. Cachin, P. Clifford, A. De Schryver, G. DE-Thé, V. Diehl and G. KLEIN. 1970b. Antibodies to Epstein-Barr virus in nasopharyngeal carcinoma, other head and neck neoplasms and control groups. J. Nat. Cancer Inst. 44: 225 .

Hinuma, Y., M. Kohn, J. Yamaguchi, D. J. Wudarski, J. R. BlakesleE and J. T. Grace. 1967. Immunofluorescence and herpes-type virus particles in the P3HR-1 Burkitt lymphoma cell line. J. Virol. 1: 1045.

JondAl, M. and G. KLEIN. 1973. Surface markers on human band I lymphocytes. II. Presence of EpsteinBarr virus receptors on B lymphocytes. J. Exp. Med. 138: 1365.

Lindahl, T., G. Klein, B. Reedman, B. Johannson and S. Singh. 1974. Relationship between Epstein-Barr virus DNA and the EBV determined nuclear antigen (EBNA) in Burkitt's lymphoma biopsies and other lymphoproliferative malignancies. Int. J. Cancer 13:764.

MCAllister, R. 1973. Viruses in human carcinogenesis. In Progress in medical virology (ed. J. L. Melnick) vol. 16, pp. 48-85. Karger, Basel.

Miller, G., T. Shope, H. Lisco, D. Stitt and M. Lipman. 1972. Epstein-Barr virus: Transformation, cytopathic changes and viral antigens in squirrel monkey and marmoset leukocytes. Proc. Nat. Acad. Sci. 69: 383. 
Nonoyama, M. and S. Pagano. 1971. Detection of EpsteinBarr viral genome in nonproductive cells. Nature New Biol. 233: 103.

1973. Homology between Epstein-Barr virus DNA and viral DNA from Burkitt's lymphoma and nasopharyngeal carcinoma determined by DNA-DNA reassociation kinetics. Nature 242: 44.

Pope, J. H., M. K. Horne and W. ScotT. 1968. Transformation of foetal human leucocytes in vitro by filtrates of a human leukaemia cell line containing herpes-like virus. Int. J. Cancer 3: 857.

ReEdman, B. M. and G. KLein. 1973. Cellular localization of an EBV-associated complement-fixing antigen in producer and nonproducer lymphoblastoid cell lines. Int. J. Cancer 11: 499.

Reedman, B. M., G. Klein, J. H. Pope, M. K. Walters, J. Hilger, S. Singh and B. Johannson. 1974. EpsteinBarr virus-associated complement-fixing and nuclear antigens on Burkitt's lymphoma biopsies. Int. J. Cancer 13:755.

SChNeIDER, U. and H. zUR HAUSEN. 1975. Epstein-Barr virus-induced transformation of human leukocytes after cell fractionation. Int. J. Cancer (in press).

Schulte-Holthausen, H. and H. zur Hausen. 1970. Partial purification of the Epstein-Barr virus and some properties of its DNA. Virology 40: 776.

Shanmugaratnam, K. 1972. The pathology of nasopharyngeal carcinoma. A review. In Herpesviruses and oncogenesis (ed. Biggs et al.) pp. 239-248. IARC, Lyon.
Shope, T., D. Dechairo and G. Miller. 1973. Malignant lymphoma in cottontop marmosets following inoculation of Epstein-Barr virus. Proc. Nat. Acad. Sci. 70: 2487.

Wetmur, J. G. and N. Davidson. 1968. Kinetics of renaturation of DNA. J. Mol. Biol. 31: 349.

Wolf, H., H. zUR HAusen and V. Becker. 1973. EB-viral genomes in epithelial nasopharyngeal carcinoma cells. Nature New Biol. 244: 245.

zur Hausen, H., W. Meinhof, W. Scheiber, and G. W. BorNKAMm. 1974a. Attempts to detect virus-specific DNA in human tumors. I. Nucleic acid hybridizations with complementary RNA of human wart virus. Int. J. Cancer 13: 650.

zur Hausen, H., V. Diehl, H. Wolf, H. Schulte-HoltHAUSEN and U. SchNeIDER. 1972. Occurrence of Epstein Barr virus genomes in human lymphoblastoid cell lines. Nature New Biol. 237: 189.

zur Hausen, H., H. Schulte-Holthausen, H. Wolf, K. DörRies and H. EGGER. 1974b. Attempts to detect virus-specific DNA in human tumors. II. Nucleic acid hybridization with complementary RNA of human herpes-group viruses. Int. J. Cancer 13: 657.

zur Hausen, H., H. Schulte-Holthausen, G. Klein, G. Henle, W. Henle, P. Clifford and L. Santesson. 1970. EBV-DNA in biopsies of Burkitt tumors and anaplastic carcinomas of the nasopharynx. Nature 228: 1056. 